\title{
A FINALIDADE EXTRAFISCAL DO TRIBUTO E AS POLÍTICAS PÚBLICAS NO BRASIL
}

\author{
Daniel Cavalcante Silva*
}

\section{Introdução}

O presente estudo visa à realização de uma análise sistemática sobre a utilização da finalidade extrafiscal da norma tributária como instrumento de implementação de políticas públicas no Brasil. Ao estudar a política pública implementada por intermédio da finalidade extrafiscal da norma tributária, o presente trabalho visa afastar a falsa noção de ser a extrafiscalidade algo meramente ocasional ou algo que seja parte secundária do fenômeno do tributo. Como é cediço, diversamente da imposição tradicional (tributação fiscal), que visa exclusivamente à arrecadação de recursos financeiros (fiscais) para promover o custeio dos serviços públicos, a denominada tributação extrafiscal é aquela orientada para fins outros que não a captação de recursos para o erário. Dessa forma, inserem-se como objetivos da extrafiscalidade: a redistribuição da renda e da terra, a defesa da economia nacional, a orientação dos investimentos para setores produtivos ou mais adequados ao interesse público, a promoção do desenvolvimento regional ou setorial e, sobretudo, como mecanismo de implementação de políticas públicas.

Dentro dessa perspectiva, observa-se que a implementação de políticas públicas por intermédio do tributo, subretudo em face da sua finalidade extrafiscal, tem a propriedade de corrigir externalidades, positivas e negativas. Nesse sentido, a tributação, como mecanismo de implementação de políticas públicas, pode ter como propósito, por exemplo, incentivar a geração de empregos ou ser utilizada como instrumento para viabilizar o ingresso de estudantes carentes ao ensino superior.

Na verdade, a finalidade extrafiscal da norma tributária, de acordo com os preceitos doutrinários e normativos, passa a ser um arranjo institucional legítimo na formulação, mecanização e implementação para que uma política pública seja viável. Essa

\footnotetext{
* Advogado e Diretor-Executivo do escritório MBSC Advogados; especialista (MBA) em Direito e Política Tributária pela FGV - Núcleo Brasília; Mestrando em Direito e Políticas Públicas pelo Centro Universitário de Brasília (UniCEUB); Membro honorário da Associação Internacional dos Jovens Advogados (AIJA) e membro honorário da Associação Internacional dos Advogados (AIA); Membro do Grupo de Pesquisa em Finanças Públicas no Estado Contemporâneo. E-mail: daniel@mbsc.com.br ou danielcasi@uol.com.br
} 
abordagem, situada no Sistema Tributário Brasileiro a partir dos objetivos extrafiscais dos tributos e seus valores jurídico-sociais implícitos e explícitos na Carta Magna, tem por intuito fornecer subsídio para que o formulador de políticas públicas possa, em razão da falta ou a incipiência de recursos financeiros, conceber o desenho institucional de uma política pública.

A análise em epígrafe traz elementos conceituais e fundamentos constitucionais para a extrafiscalidade da norma tributária, sobretudo como fundamento para que a implementação de políticas públicas possa se sobressair quando eventualmente existirem dúvidas quanto a sua legitimidade.

\section{A finalidade extrafiscal da norma tributária como mecanismo de implementação de políticas públicas}

Para que as práticas e os objetivos sumariados constitucionalmente sejam implementados, as ciências que se ocupam das respectivas áreas pressupõem a capacidade do Estado tributar, isto é, exercer ingerência sobre a esfera dos indivíduos. Ao traduzir esse fenômeno em linguagem do Direito, é necessário sustentar um fundamento jurídico que permita ao Estado tributar, afastando os interesses individuais contrários à incidência tributária. Revela-se, desse modo, outra faceta do corolário da supremacia do interesse público sobre o interesse do particular no Direito Tributário.

Nesse sentido, a atividade financeira do Estado passou a ter uma natureza nitidamente extrafiscal, sendo utilizada não apenas para fins de natureza fiscal, mas também política, econômica e social, desde o momento em que este Estado tornou-se um agente interventor do desenvolvimento e do bem-estar social, deixando de ser, simplesmente, um mediador distanciado dos debates sociais.

Há muito vem se discutindo os institutos da fiscalidade, da extrafiscalidade e da parafiscalidade como critérios finalísticos dos tributos. Entretanto, até o presente momento não se chegou a nenhum denominador comum no que concerne às suas respectivas definições e valores finalísticos que o legislador desejou imprimir na lei tributária. Ademais, poucas são as referências doutrinárias no direito positivo que tratam o tema substancialmente. Em restrição à temática, aborda-se apenas a finalidade extrafiscal do tributo.

A atividade financeira que o Estado exerce com o intuito de ordenar as relações sociais e econômicas interferindo, por exemplo, no mercado, é denominada como atividade extrafiscal. Com efeito, essa atuação extrafiscal do Estado não visa à obtenção de recursos para o erário público, mas apenas à atuação sobre o contexto econômico, alterando o cenário social, através, por exemplo, da tributação em gastos seletivos ou a sua retenção. Como se 
sabe, as exações fiscais são receitas derivadas, arrecadadas pelo Estado, para financiar a despesa pública. De acordo com Luciano Amaro ${ }^{1}$, a distinção entre tributos com finalidade fiscal e tributos com finalidade extrafiscal reside, exatamente, "no objetivo visado pela lei de incidência”.

Nesse sentido, Misabel Derzi, em nota de atualização do livro de Aliomar Baleeiro, preleciona que o tributo é extrafiscal quando não almeja prioritariamente prover o Estado dos meios financeiros adequados a seu custeio, mas, antes, visa a ordenar a propriedade de acordo com a sua função social ou a intervir dados conjunturais (injetando ou absorvendo a moeda em circulação) ou estruturais da economia. É cediço, no entanto, que o Estado tributa com vistas a auferir receitas e, assim, a supremacia do interesse público consubstancia o princípio da fiscalidade. Quando se apreciam objetivos outros, que se afastam da pura arrecadação, apresenta-se a extrafiscalidade. "Eis a extrafiscalidade como princípio, decorrente da supremacia do interesse público, que fundamenta, juridicamente, a tributação com fins diversos do puramente arrecadatório.”2

Portanto, a extrafiscalidade caracteriza-se pelo exercício da cobrança para atender a outros interesses, que não os de mera arrecadação de recursos financeiros. O interesse geralmente manifestado com a extrafiscalidade é o de correção de situações sociais ou econômicas anômalas. Segundo Hugo de Brito Machado, “o tributo é extrafiscal quando seu objetivo principal é a interferência no domínio econômico, para buscar um efeito diverso da simples arrecadação de recursos financeiros”3. Endossa ainda essa posição Paulo de Barros Carvalho, ao afirmar que "a forma de manejar elementos jurídicos usados na configuração dos tributos, perseguindo objetivos alheios aos meramente arrecadatórias, dá-se o nome de extrafiscalidade" ${ }^{4}$.

De acordo com tais entendimentos, pode-se inferir que a extrafiscalidade constitui-se na aplicação de um modelo jurídico-tributário para a consecução de objetivos que preponderam sobre os fins simplesmente arrecadatórios de recursos financeiros para o Estado. O valor finalístico da extrafiscalidade que o legislador incute na lei tributária, portanto, deve atender às necessidades na condução da economia ou correção de situações sociais indesejadas ou mesmo possibilidade de fomento a certas atividades ou ramo de atividades de acordo com os preceitos constitucionais.

\footnotetext{
${ }^{1}$ AMARO, Luciano. Direito tributário brasileiro. 2. ed. Revisada. São Paulo: Saraiva, 1998, p. 67.

2 GOUVÊA, Marcus de Freitas. A extrafiscalidade no direito tributário. Belo Horizonte: Editora Del Rey, 2006, p. 43.

${ }^{3}$ MACHADO, Hugo de Brito. Curso de direito tributário. São Paulo: Malheiros, 1997, pág. 129.

${ }^{4}$ CARVALHO, Paulo de Barros. Curso de direito tributário. 9. ed. rev., São Paulo: Editora Saraiva, 1997, p. 146. 
Nesse diapasão, quando o legislador institui uma lei de cunho extrafiscal, enceta providências no sentido de prestigiar algumas situações econômico-sociais. Assim, no caso da educação superior, pode-se verificar a preocupação estatal na consecução de valores sociais, conforme preconiza o art. $6^{\circ}$ da Carta Magna ${ }^{5}$. Deve-se ressaltar, além disso, o direito à educação como fundamento prestacional do Estado ${ }^{6}$. Assim, por exemplo, quando o Imposto Territorial Rural (ITR) busca atender, em primeiro plano, à finalidade de ordem social e econômica e não o incremento da receita, ao fazer incidir a exação de maneira mais onerosa, no caso dos imóveis inexplorados ou de baixa produtividade.

De acordo com a finalidade imediata supra referida, a tendência moderna do cunho extrafiscal da legislação apóia-se em orientar os indivíduos no interesse coletivo, visando organizar a vida em termos de civilidade e nivelação dos tipos e modos de viver. $A$ priori, para fundamentar qualquer teoria social aplicada, é necessário analisar a importância do princípio do bem comum e do interesse público, aspecto no qual incide a finalidade extrafiscal da lei. Modernamente, toda atividade legislativa tem se orientado para esse objetivo, que não é um objetivo meramente formal ou demasiadamente genérico e teórico, sem conteúdo determinado, mas um objetivo claro, decorrente da natureza prática das coisas em relação com o convívio social.

O conceito de bem comum incide na eterna dialética do interesse individual e o interesse coletivo. Ao singularizar o conceito de bem comum, poder-se-ia dizer que seria o bem particular de cada indivíduo, como ente de um todo social. Mas se, ao contrário, o conceito de bem comum for ampliado, observar-se-ia que o fim de cada indivíduo seria o fim do todo. Na realidade, ambos os conceitos se complementam, pois o bem da sociedade é o bem do próprio indivíduo que a compõe.

A atribuição de promover o bem comum cabe ao legislador, por intermédio de uma atuação voltada às aspirações sociais, dentre elas o dever de dirimir eventuais conflitos emanados pela própria autoridade administrativa em face dos interesses sociais. Esses interesses sociais, hodiernamente, foram diversificados e ampliados em virtude do bem comum da sociedade, como na noção de interesse público, privado, coletivo, individual, homogêneo e difuso.

\footnotetext{
5 “Art. $6^{\circ}$. São direitos sociais a educação, a saúde, o trabalho, a moradia, o lazer, a segurança, a previdência social, a proteção à maternidade e à infância, a assistência aos desamparados, na forma desta Constituição.” BRASIL. Constituição da República Federativa do Brasil. Brasília: Planalto, 2006. Disponível em: < http://www.planalto.gov.br > Acesso em: 22 nov. 2006.

6 MALISKA, Marcos Augusto. O direito à educação e a Constituição. Porto Alegre: Sérgio Fabris Editor, 2001, p. 243.

PRISMAS: Dir., Pol.Pub. e Mundial., Brasília, v.4, n, 1, p. 98-122, jan/jul. 2007 
Nesse sentido, por exemplo, a legislação do Imposto de Renda e proventos de qualquer natureza (IR) permite o abatimento de verbas gastas em determinados investimentos, tidos como de interesse social ou econômico, tal como o reflorestamento, que tem a possibilidade de justamente incentivar a formação de reservas florestais do país.

Um exemplo do entrelaçamento de efeitos fiscais e extrafiscais encontra-se na denominada Cide-Tecnologia (Contribuição de Intervenção no Domínio Econômico), criada pela Lei n. ${ }^{\circ}$ 10.168, de 29 de dezembro de 2000 e destinada a financiar (elemento fiscal) o Programa de Estímulo à Interação Universidade-Empresa para Apoio à Inovação, cujo objetivo principal é o de estimular o desenvolvimento tecnológico brasileiro (elemento extrafiscal), mediante programas de pesquisa científica e tecnológica cooperativa entre universidades, centros de pesquisa e o setor produtivo.

A Cide-Tecnologia somente é devida pelas pessoas jurídicas que pagam royalties a titulares de direitos de propriedade intelectual residentes ou domiciliados no exterior. Com esse tributo, o Estado brasileiro tem a possibilidade de desestimular esse tipo de pagamento tornando-o mais oneroso, reduzindo assim o gasto de divisas, ao mesmo tempo em que incentiva a demanda por tecnologia doméstica com vistas a contribuir para o desenvolvimento autóctone. Enquanto isso não se materializa, a receita planejada com a Cide, que se projeta declinante em razão do antevisto sucesso do programa, financiará a produção de tecnologia destinada a atender aquela demanda nova por inovações domésticas.

A extrafiscalidade, portanto, fica adstrita ao interesse público que, parafraseando Hely Lopes Meirelles, "são as aspirações ou vantagens licitamente almejadas por toda a comunidade administrativa, ou parte expressiva de seus membros". ${ }^{7}$ A finalidade da extrafiscalidade da lei tributária, aplicada em vários campos de atuação do homem, repousa no bem comum revestido de utilidade coletiva.

Enfim, os efeitos extrafiscais da norma tributária utilizam-se do instrumento financeiro para a provocação de certos resultados econômico-sociais, como reprimir inflação e o desemprego, restaurar a prosperidade, proteger a indústria nacional, promover o desenvolvimento econômico ou o nivelamento das fortunas ou a correção da iniqüidade na distribuição da renda nacional, entre outros objetivos não menos nobres.

\footnotetext{
${ }^{7}$ MEIRELLES, Hely Lopes. Direito administrativo brasileiro. São Paulo: Editora Malheiros, 1997, pág. 80. PRISMAS: Dir., Pol.Pub. e Mundial., Brasília, v.4, n, 1, p. 98-122, jan/jul. 2007
} 


\subsection{A origem da extrafiscalidade: a parafiscalidade}

Como finalidade imediata do tributo, a extrafiscalidade teve origem histórica nas contribuições parafiscais em geral e nas Contribuições de Intervenção no Domínio Econômico (CIDE), desde a sua gênese francesa e italiana ${ }^{8}$, e por desígnio constitucional no Brasil (art. 149 da Constituição da República), sendo um instituto fadado a desempenhar um papel dublê aos tributos contemporâneos.

A parafiscalidade e a contribuição parafiscal nasceram com a intervenção estatal na ordem econômica e social e com a descentralização administrativa necessária à sua implementação. Daí a essencial, ontológica e necessária afetação da contribuição como receita própria das entidades da Administração Pública indireta incumbidas daquela nova tarefa. A terminologia parafiscalidade exprime um fenômeno histórico que não pode ser olvidado no estudo das contribuições, que são apenas a conseqüência fiscal (ou parafiscal) da descentralização administrativa que se verificou no mundo, especialmente a partir dos anos 1930 e intensamente após a Segunda Guerra mundial ${ }^{9}$.

A criação de entidades paraestatais, com personalidade jurídica própria, gravitando em torno do Estado, mais especificamente na administração indireta, e assumindo funções das quais a Administração direta não seria capaz, fez surgir a necessidade de novas receitas paralelas ao orçamento fiscal que financiassem as respectivas despesas, assim, descentralizadas ${ }^{10}$, daí a origem do termo parafiscal. Afetava-se um patrimônio estatal a um novo ente administrativo. Afetava-se uma receita própria para que com ela se desincumbisse da tarefa a ser descentralizadamente executada. Surgem, assim, as chamadas receitas parafiscais.

José Marcos Domingues de Oliveira conceitua a contribuição parafiscal “como o tributo devido a entidades paraestatais em razão de atividades públicas especiais por elas desenvolvidas e as classifica em contribuições sociais ou assistenciais, econômicas ou de intervenção na ordem econômica, coorporativas ou profissionais.”"11

As contribuições parafiscais chegaram no Brasil na década de quarenta, pelas mãos do tipo contribuição previdenciária, financiadora de incipiente sistema de Caixas de

\footnotetext{
${ }^{8}$ OLIVEIRA, José Marcos Domingues de. O Conteúdo da extrafiscalidade e o papel das Cides. Efeitos decorrentes da não-utilização dos recursos arrecadados ou da aplicação em finalidade diversa. Revista Dialética de Direito Tributário, São Paulo: Dialética, n. 131, p. 47, ago. 2006.

${ }^{9}$ Idem, p. 37.

${ }^{10}$ Idem, p. 37.

${ }^{11}$ OLIVEIRA, José Marcos Domingues de. Contribuições sociais, In Cadernos de pesquisas tributárias. v. 17, São Paulo: Resenha Tributária e Centro de Extensão Universitária, 1992, p. 136.

PRISMAS: Dir., Pol.Pub. e Mundial., Brasília, v.4, n, 1, p. 98-122, jan/jul. 2007 
Aposentadoria e Pensões, para daí alcançarem status constitucional em $1969^{12}$. Veicularamse, depois, expressamente como "instrumento de atuação” (custeio) nas áreas de intervenção da União Federal dos domínios sociais, corporativos e econômicos. Tiveram origem na França, para subsidiar políticas de desenvolvimento, e na Itália, para financiar a política sindical, circunstâncias que fizeram surgir a célebre polêmica entre Mérigot e Morselli a respeito de sua singularidade de fundamento numa nova solidariedade, a afastar delas a irrestrita obediência à legalidade tributária ${ }^{13}$.

Essa relação intrínseca entre as contribuições parafiscais e a intervenção do Estado na Ordem Econômica determinou, por um lado, a autonominação e personificação de novos serviços estatais e, de outro, a afetação das novas receitas aos cofres das recentes entidades paraestatais encarregadas de desempenhar aquele novo tipo de atuação estatal. Nesse sentido, ressalta Casalta Nabais:

Quanto às contribuições, tributos ou receitas parafiscais [...] se caracterizam por serem tributos [...] que são cobrados das despesas de pessoas colectivas públicas não territoriais [...], tributos objecto de uma verdadeira consignação subjetiva de receitas. ${ }^{14}$

No Brasil, a afetação das contribuições parafiscais às entidades paraestatais ocorreu em relação a várias instituições, como aos Institutos de Previdência, a Embratur, entre outras. Embora à mercê de apenas uma jurisprudência leniente do Supremo Tribunal Federal que desde o Recurso Extraordinário n. ${ }^{0}$ 138.824-CE ${ }^{15}$ admite a centralização da arrecadação das contribuições, é assente no Direito brasileiro que as contribuições se distinguem no sistema tributário pátrio como tributos finalísticos. Esses tributos são aqueles cuja instituição só se pode dar para atender a uma finalidade expressamente admitida na Constituição, por isso mesmo, os respectivos recursos devem ser consumidos na finalidade assinalada.

Em suma, a finalidade parafiscal do tributo destina-se historicamente ao custeio do parafisco e, contemporaneamente, serve de instrumento à adesão de políticas públicas de cunho regulatório (Cide-Tecnologia, Lei n. ${ }^{\circ}$ 10.168, de 29 de dezembro de 2000), ou transformadora das estruturas (Cide-Combustíveis, Lei n. ${ }^{\circ}$ 10.336, de 19 de dezembro de 2001) ${ }^{16}$. Cumpre ressaltar que diante do novo cenário do Estado contemporâneo, conforme

\footnotetext{
${ }^{12}$ Artigos 18 e 19 da Constituição brasileira de 1967. Disponível em: < http://www.planalto.gov.br > Acesso: 01 dez. 2006.

${ }^{13}$ FERNANDES, Simone Lemos. Contribuições neocorporativas. Belo Horizonte: Del Rey, 2005, p. 53.

${ }^{14}$ NABAIS, Casalta. Direito fiscal. 2. ed. Coimbra: Almedina, Apud OLIVEIRA, José Marcos Domingues de. Contribuições sociais, In Cadernos de pesquisas tributárias. v. 17, São Paulo: Resenha Tributária e Centro de Extensão Universitária, 1992., p. 48.

${ }^{15}$ Disponível em: < http://www.stf.gov.br $>$ Acesso em: 01 dez. 2006.

${ }^{16}$ Disponível em: < http://www.planalto.gov.br $>$ Acesso em: 01 dez. 2006.

PRISMAS: Dir., Pol.Pub. e Mundial., Brasília, v.4, n, 1, p. 98-122, jan/jul. 2007 
assente a doutrina nacional, a parafiscalidade faria parte da extrafiscalidade, sendo aquela elemento conceitual da finalidade extrafiscal. Nesse sentido, como as finalidades de ambas estão imbricadas, não faz mais sentido distingui-las.

\section{A tributação extrafiscal e sua aplicabilidade em face dos princípios constitucionais}

Os constitucionalistas norte-americanos, seguindo o rastro jurisprudencial dos tribunais do seu país, arquitetaram uma distinção entre os tributos cobrados com fundamento no "poder de tributar" e os exigidos sob o amparo do "poder de polícia”, ambos inerentes e inseparáveis do Estado. Praticamente, essa diferença equivale à de "tributos puramente fiscais” e “tributos extrafiscais".

Do ponto de vista estritamente jurídico, a separação das duas categorias supracitadas permite aos tribunais anuírem com limitações ou cláusulas constitucionais. Se o fim almejado pelo poder de polícia está dentro da competência da pessoa de direito público que exige tributo, esse é tolerado no interesse da proteção à vida, à segurança, à liberdade, à saúde, à higiene, ao bem-estar e à moralidade dos cidadãos.

Seguindo essa tendência, impostos confiscatórios e proibitivos, que se atritam com os direitos e garantias constitucionais da propriedade ou do exercício de profissões e atividades lícitas muitas vezes são tolerados pela jurisprudência norte-americana como manifestações do poder de polícia, desde que, em caso concreto, se apure sua eficácia na defesa da segurança, saúde e bem-estar do povo. Essa é a atribuição moderna da tributação extrafiscal e a gênese da possibilidade de afastamento da aplicabilidade de princípios constitucionais, conforme prognosticava Aliomar Baleeiro ${ }^{17}$.

Aliomar Baleeiro tinha razão, de certa maneira, em tangenciar a jurisprudência americana e correlacioná-la com a prática jurisprudencial brasileira, pois alíquotas percentuais progressivas ou regressivas de natureza extrafiscal ou política, hipóteses em que se enquadram as alíquotas com função punitiva ou seletiva, que variam segundo critérios relacionados com políticas públicas. As alíquotas assumem a função de meios extrafiscais de intervenção no domínio econômico ou social, não possuindo fins essencialmente arrecadatórios.

Quando se pretende uma intervenção por intermédio de procedimentos ou modelos tributários aplicáveis, o Estado ora usa dos efeitos drásticos que uma imposição

\footnotetext{
${ }^{17}$ BALEEIRO, Aliomar. Introdução à ciência das finanças. 14.ed., atualizada por Flávio Bauer Novelli, Rio de Janeiro: Editora Forense, 1995, p. 177. 
produz sobre os preços e o valor, ora afasta esses efeitos por meio de imunidades e isenções, discriminando, para esse fim, as coisas, fatos ou atividades, que deseja preservar e encorajar.

Para fins de esclarecimento, deve-se atentar ao fato de que uma das mais antigas aplicações do imposto para desempenho de funções extrafiscais é a exigência de direitos alfandegários altamente onerosos para proteção da produção nacional, já que essa política provoca encarecimento das mercadorias estrangeiras, afastando-as da concorrência ou permitindo que as nacionais se possam vender por preços mais gratificantes.

Por outro lado, o mesmo resultado pode ser obtido por intermédio de isenções a certos ramos de atividade nacional, de forma que o custo da produção desta fique na paridade da mercadoria importada. Em geral, essas duas formas se ordenam ou harmonizam para o mesmo fim.

A tributação fundada em critérios político-econômicos baseia-se nos efeitos da tributação sobre a repartição de encargos públicos e sobre a redistribuição da renda nacional. Evidentemente, qualquer técnica de tributação extrafiscal em bases racionais pressupõe o estudo dos efeitos de cada imposto em dadas conjunturas, notadamente, as tendências de ordem econômica.

A intervenção do Estado por meio de tributos extrafiscais ou do poder de polícia oferece vasta casuística na legislação e jurisprudência pátria. Inicialmente, existem doutrinadores que entendem ser incompatíveis determinados princípios tributários com a tributação extrafiscal. O aspecto supracitado traz à baila a questão da tributação exacerbada por razões extrafiscais, que poderia violar, entre outros, o princípio da capacidade contributiva.

Juliani Fonrouge, com a oposição de outros doutrinadores, entende que o princípio da capacidade contributiva é incompatível com a tributação extrafiscal. As isenções e outras técnicas de exoneração fiscal para alavancar o desenvolvimento econômico, segundo o mestre portenho, partem da idéia de que os empreendedores possuem elevada capacidade econômica, "tanto que investem dinheiro em atividades empresariais em troca de aliciantes fiscais" ${ }^{\prime 18}$.

Por outro lado, conforme o mesmo autor, as técnicas inibitórias de extrafiscalidade só são possíveis pela exacerbação dos encargos fiscais, tornando proibitivos certos consumos e hiperonerosas certas situações. Pode-se verificar o seguinte exemplo com o ITR e IPTU progressivos. O primeiro para desestimular o latifúndio, o ausentismo e a improdutividade

\footnotetext{
${ }^{18}$ FONROUGE, Juliani. Derecho financiero. 3. ed., v. I, Buenos Aires: Editora Depalma, 1976, p. 126. 
rural, e o segundo para coibir a especulação imobiliária urbana e a disfunção social da propriedade nas cidades.

Sem a exacerbação da tributação não haveria como praticar a extrafiscalidade, que se caracterizaria justamente pelo uso e manejo dos tributos, com a finalidade de atingir alvos diferentes da simples arrecadação de dinheiro. Nesses casos, conjetura Juliani Fonrouge, a consideração da capacidade contributiva, que não está em causa, seria demasia.

Na realidade, a tese poderia ser melhor esclarecida quando se analisa alguns casos práticos em que, tanto a majoração quanto a redução de impostos, seguindo um critério extrafiscal, violariam o princípio da capacidade contributiva. O primeiro caso seria a isenção de taxa judiciária para os pobres e a redução ou mesmo isenção da contribuição de melhoria em relação aos miseráveis que, sem querer, foram beneficiados em suas humílimas residências por obras públicas extremamente valorizadas. Obrigá-los a vender suas propriedades para pagar a contribuição seria impensável e inadmissível.

Em outro caso, nos tributos chamados indiretos, ou de mercado, em que entra em cena o contribuinte de fato, a capacidade contributiva realizar-se-ia imperfeitamente no caso da extrafiscalidade. É o exemplo das alíquotas menos gravosas do IPI e do ICMS. Supõe-se que o de menor renda (contribuinte de fato) consome artigos necessários tão-somente a uma existência sofrida e, por isso, as alíquotas são reduzidas, ou até mesmo as concessões de isenções. Ocorre que tanto um José da Silva quanto um Ermírio de Moraes compram feijão, beneficiando-se dos favores pensados para José. De acordo com a tese de Juliani Fonrouge, esposada inclusive por juristas nacionais como Sacha Calmon Navarro Coêlho, a extrafiscalidade sempre entraria em choque com o princípio da capacidade contributiva.

Juliani Fonrouge conclui que o princípio da capacidade contributiva junto com outros princípios, tais como o da igualdade e o da generalidade, poderiam atuar para o controle político e jurisdicional da tributação pervertida ou das perversões da extrafiscalidade. É de suma importância observar que a tributação extrafiscal converge, geralmente, com os princípios tributário-constitucionais, razão pela qual não se há como falar em afastabilidade de princípios constitucionais.

No entanto, mesmo com a observância divergente de parte da doutrina, os tribunais pátrios e outra gama de doutrinadores entendem pela aplicabilidade do tributo extrafiscal quando os objetivos sejam alheios aos meramente arrecadatórios, ou seja, quando se pretenda prestigiar situações sociais, política e economicamente valiosas. A utilização do imposto com caráter de extrafiscalidade é expediente largamente aceito na doutrina jurídica, nacional e internacional. Hely Lopes Meirelles preleciona: 
A extrafiscalidade é a utilização do tributo como meio de fomento ou de desestímulo a atividades reputadas convenientes ou inconvenientes à comunidade. É ato de polícia fiscal, isto é, de ação de governo para o atingimento de fins sociais através da maior ou menor imposição tributária. $[\ldots]$

Modernamente, os tributos são usados como instrumento auxiliar do poder regulatório do Estado sobre a propriedade particular e as atividades privadas que tenham implicações com o bem-estar social. Até mesmo o Direito norteamericano, tão cioso das liberdades individuais, admite essa função extrafiscal dos tributos, para o incentivo ou repressão da conduta do particular. [..]

Com efeito, através da agravação do imposto podem-se afastar certas atividades ou modificar-se a atitude dos particulares reputadas contrárias ao interesse público, como pelo abrandamento da tributação pode-se incentivar a conduta individual conveniente à comunidade. ${ }^{19}$

Dessa forma, enquanto os impostos chamados fiscais destinam-se somente à obtenção de receitas para o gasto público, os impostos extrafiscais possuem fins diversos, para abranger os de política econômica ou social, de política administrativa, de política demográfica, de política sanitária, de política cultural e até mesmo de política ambiental e de proteção dos recursos naturais não renováveis.

A Constituição da República adotou a extrafiscalidade como recurso normal do procedimento tributário, sobretudo no que diz respeito à implementação de políticas públicas, ao permitir a exacerbação do ônus fiscal ou de suavizá-lo, em função dos objetivos pretendidos. De acordo com Hugo de Brito Machado:

O objetivo do tributo sempre foi o de carrear recursos financeiros para o Estado. No mundo moderno, todavia, o tributo é largamente utilizado com o objetivo de interferir na economia privada, estimulando atividades, setores econômicos ou regiões, desestimulando o consumo de certos bens e produzindo finalmente os efeitos mais diversos na economia. A esta função moderna do tributo se denomina função extrafiscal. ${ }^{20}$

Na verdade, o entendimento da não aplicação da finalidade extrafiscal do tributo em face de princípios tributário-constitucionais perpassa ao vetusto entendimento de que o tema seria exterior ao direito e circunscrito à esfera econômica, integrando os domínios da Política Pública Fiscal, ainda que não pudesse prescindir dos regramentos jurídicoconstitucionais, até mesmo pela possibilidade de, obliquamente, ofender direitos ou garantias individuais. No entanto, hodiernamente, o ordenamento pátrio encampou a extrafiscalidade sob o pálio do direito econômico.

\footnotetext{
${ }^{19}$ MEIRELLES, Hely Lopes. Direito municipal brasileiro. 6. ed. atualizada por Izabel C. L. Monteiro e Yara D. P. Monteiro. São Paulo: Editora Malheiros, 1993, p. 151.

${ }^{20}$ MACHADO, Hugo de Brito. Op. Cit., p. 130.

PRISMAS: Dir., Pol.Pub. e Mundial., Brasília, v.4, n, 1, p. 98-122, jan/jul. 2007 
Em face desses argumentos, pode-se inferir que a complexidade dos fenômenos econômico-financeiros justifica que o Estado institua tributos com a finalidade de perseguir outros objetivos, diversos da mera obtenção de receita para custear suas atividades típicas, podendo, assim, interferir no direito de propriedade e/ou ao livre exercício de trabalho, profissão ou ofício, caracterizando-se, portanto, a finalidade extrafiscal do tributo.

\title{
3.1 Entendimento jurisprudencial sobre a extrafiscalidade na implementação de políticas públicas
}

Para justificar a importância da extrafiscalidade, o Supremo Tribunal Federal já se posicionou no sentido de que o tributo extrafiscal prepondera, em alguns casos, sobre os princípios tributário-constitucionais. Por conseguinte, pode-se citar o seguinte julgado do Supremo Tribunal Federal:

\author{
ADI 1276 / SP - SÃO PAULO \\ AÇÃO DIRETA DE INCONSTITUCIONALIDADE \\ Relator(a): Min. ELLEN GRACIE \\ Julgamento: 29/08/2002Ｏ́n～Órgão Julgador: Tribunal Pleno \\ Publicação: DJ DATA-29-11-2002 PP-00017 EMENT VOL-02093-01 PP- \\ 00076
}

Ao instituir incentivos fiscais a empresas que contratam empregados com mais de quarenta anos, a Assembléia Legislativa Paulista usou o caráter extrafiscal que pode ser conferido aos tributos, para estimular conduta por parte do contribuinte, sem violar os princípios da igualdade e da isonomia. Procede a alegação de inconstitucionalidade do item 1 do $\S 2^{\circ}$ do art. $1^{\circ}$, da Lei 9.085, de 17/02/95, do Estado de São Paulo, por violação ao disposto no art. 155, § 2 , XII, g, da Constituição Federal. Em diversas ocasiões, este Supremo Tribunal já se manifestou no sentido de que isenções de ICMS dependem de deliberações dos Estados e do Distrito Federal, não sendo possível a concessão unilateral de benefícios fiscais. Precedentes ADIMC 1.557 (DJ 31/08/01), a ADIMC 2.439 (DJ 14/09/01) e a ADIMC 1.467 (DJ 14/03/97). Ante a declaração de inconstitucionalidade do incentivo dado ao ICMS, o disposto no $\S 3^{\circ}$ do art. $1^{\circ}$ desta lei, deverá ter sua aplicação restrita ao IPVA. Procedência, em parte, da ação. (grifos editados)

Deve-se ressaltar que essa Lei Estadual foi declarada inconstitucional em face de aspectos formais e não por causa do caráter extrafiscal, como a própria leitura do acórdão explicita. Na verdade, essa "preponderância” do aspecto extrafiscal sobre alguns princípios tributário-constitucionais está respaldada sob o prisma de um princípio constitucional implícito, que é o princípio da proporcionalidade. O Supremo Tribunal Federal, ao analisar a extrafiscalidade da lei paulista, adotou o princípio da proporcionalidade para condicionar o 
exercício da função legislativa, baseando-se em uma visão estrutural e funcional desse princípio na justificativa de sua qualidade heterônoma, impositiva de limites não somente negativos, mas especialmente positivos, à ação do legislador.

Sob o prisma do Direito Econômico, os tributos cuja finalidade seja essencialmente extrafiscal devem obedecer ao princípio da proporcionalidade ou da proibição do excesso, cunhado pelo Direito Constitucional alemão em aperfeiçoamento à noção de poder de polícia, oriunda do Direito Constitucional norte-americano como fundamento da extrafiscalidade.

O princípio da proporcionalidade ou da proibição do excesso desdobra-se nos seguintes aspectos: legitimidade dos fins, significando a relevância constitucional dos fins buscados; efetividade do meio, pela qual o meio de ser capaz de realizar o fim constitucionalmente legítimo; imprescindibilidade do meio, de modo que a finalidade perseguida deve excluir a adoção de outro meio, pelo menos tão eficiente quanto o tributo extrafiscal e, por fim, a razoabilidade ou proporcionalidade em sentido estrito, pelo qual o sacrifício exigido deve estar em relação direta, para mais, com a relevância da finalidade objetivada.

Tais aspectos também se constituem com elementos do princípio da proporcionalidade, cuja explicação pode detectar ou repelir vícios substanciais da lei em uma perspectiva diversa daquela tradicional, quando está em causa a mera compatibilidade lógicoformal das normas constitucionais.

Desse modo, os elementos que constituem o princípio da proporcionalidade são, segundo Suzana de Toledo Barros ${ }^{21}$ : o juízo de adequação ou idoneidade (medida adotada para respeitar a congruência entre na relação meio-fim - idoneidade à consecução da finalidade perseguida), juízo de necessidade (meio mais idôneo e de conseqüências menos gravosas) e o princípio da proporcionalidade em sentido estrito (otimização de possibilidade jurídica - exaltação da idéia de equilíbrio entre valores e bens).

Seguindo tal entendimento, o Supremo Tribunal Federal julgou esse pleito judicial na perspectiva de que, ao instituir incentivos fiscais à empresas contratantes de empregados com mais de quarenta anos, a Assembléia Legislativa Paulista usou apropriadamente o caráter extrafiscal que pode ser conferido aos tributos. Trata-se de uma ponderação entre a medida adotada para respeitar a congruência entre na relação meio-fim, o meio mais idôneo, as conseqüências menos agravantes e a exaltação da idéia de equilíbrio entre valores e bens.

\footnotetext{
${ }^{21}$ BARROS. Suzana de Toledo. O princípio da proporcionalidade e o controle de constitucionalidade das leis restritivas de direitos fundamentais. 2. ed. Brasília: Editora Brasília Jurídica, 2000, p. 74. 
Ora, de acordo com esse aspecto, o STF entende que a instituição de incentivos fiscais para empresas que contratassem empregados com mais de quarenta anos estaria respeitando a relação entre meio e fim da lei. Ou seja, um incentivo seria atribuído a quem contratasse empregados com mais de quarenta anos. Tal atitude geraria conseqüências menos gravosas e haveria um equilíbrio entre valores e bens da sociedade, quais sejam, o direito ao trabalho e o respeito aos idosos que pudessem estar fora do mercado de trabalho.

Nesse caso, não haveria o afastamento da aplicabilidade de princípios tributárioconstitucionais, mas a preponderância da extrafiscalidade, com base no princípio da proporcionalidade, sem violar os princípios da igualdade e da isonomia. Na mesma perspectiva, pode-se verificar, novamente, a "preponderância” do aspecto extrafiscal sobre outros princípios tributário-constitucionais, conforme o julgado a seguir:

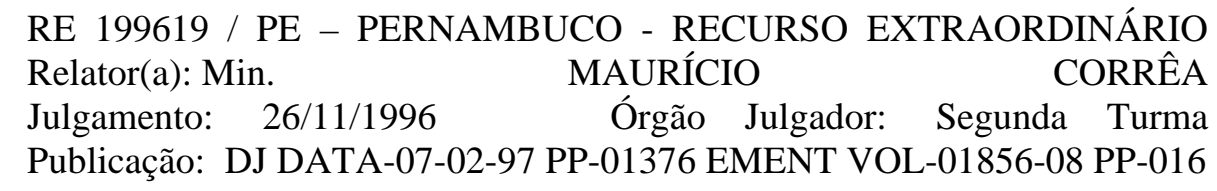

EMENTA: CONSTITUCIONAL. TRIBUTÁRIO. IMPOSTO DE IMPORTAÇÃO DE VEÍCULOS USADOS. VEDAÇÃO: PORTARIA N ${ }^{\circ}$ 8/91-DECEX. VULNERAÇÃO AOS PRINCÍPIOS DA ISONOMIA E DA LEGALIDADE. INEXISTÊNCIA. RECURSO CONHECIDO E PROVIDO.

1. Imposto de importação. Função predominantemente extrafiscal, por ser muito mais um instrumento de proteção da indústria nacional do que de arrecadação de recursos financeiros, sendo valioso instrumento de política econômica. 2. A Constituição Federal estabelece que é da competência privativa da União legislar sobre comércio exterior e atribui ao Ministério da Fazenda a sua fiscalização e o seu controle, atribuições essas essenciais à defesa dos interesses fazendários nacionais. 2.1. Importação de veículos usados. Vedação. Portaria DECEX ñ 08/91. Legalidade. A competência do Departamento de Comércio Exterior, órgão do Ministério da Fazenda, encontra-se disciplinada no art. 165 do Decreto $n^{\circ}$ 99.244/90 e, dentre outras atribuições, compete-lhe a de emitir guia de importação, de fiscalizar o comércio exterior e a elaboração de normas necessárias à implementação da política de comércio exterior. Improcedência da alegação de ofensa ao princípio da legalidade. 3. Princípio da isonomia. Vulneração. Inexistência. Os conceitos de igualdade e de desigualdade são relativos: impõem a confrontação e o contraste entre duas ou várias situações, pelo que onde só uma existe não é possível indagar sobre tratamento igual ou discriminatório. 3.1. A restrição à importação de bens de consumo usados tem como destinatários os importadores em geral, sejam pessoas jurídicas ou físicas. Lícita, pois, a restrição à importação de veículos usados. Recurso extraordinário conhecido e provido. (Grifos editados)

No caso supracitado, o STF levou em consideração a isenção extrafiscal como medida de natureza incentivadora. Nessa circunstância, o STF utilizou-se de um critério imediato (extrafiscalidade) na aplicação de um caso específico na plenitude da sua realidade. 
Implicitamente, a Corte Suprema empregou o princípio da proporcionalidade em sentido estrito, exaltando da idéia de equilíbrio entre valores e bens, visando muito mais à proteção da indústria nacional do que à arrecadação de recursos financeiros.

Para as isenções extrafiscais, de natureza incentivadora, não se pode exigir isonomia, pela capacidade contributiva, dos sujeitos passivos nas regras discriminatórias que objetivem compensar ou minorar as desigualdades derivadas de outros fatores. O principio da isonomia permite ao legislador fazer discriminações que atendam situações desiguais (o que parte do que a doutrina chama de “desisonomia seletiva”), desde que o critério discriminatório não seja puramente arbitrário, existindo razões valiosas, de ordem econômica e/ou social. É por essa razão que o princípio da proporcionalidade é sempre utilizado na possibilidade de "afastamento" da aplicação de outros princípios tributário-constitucionais.

Outro entendimento pela aplicabilidade do critério extrafiscal diz respeito à progressividade do Imposto Predial e Territorial Urbano (IPTU). O STF entende que a única progressividade admitida é a de caráter extrafiscal, como sendo instrumento de efetivação da função social da propriedade, de acordo com os preceitos normativos do art. 182, $\S 4^{\circ}$, da Constituição da República. Nesse caso, essa aplicação está condicionada, ainda, à existência de lei federal, bem como de previsão no plano diretor do município. Contudo, refere-se à progressividade no tempo, como forma de desestimular a propriedade não edificada, subutilizada ou não utilizada.

Por fim, vale ressaltar que não há um "afastamento" da aplicabilidade de princípios tributário-constitucionais, de acordo com os julgados da Corte Suprema, mas tão somente a preponderância do caráter extrafiscal da norma tributária, baseado em critérios de proporcionalidade. Trata-se de uma distinção metodológica no campo do Direito Tributário, sendo uma questão hermenêutica teleológica, ou seja, o conhecimento ou explicação que relaciona um fato com sua causa final.

Por outro lado, se for considerado o entendimento de que essa "preponderância" repercute no "afastamento" da aplicabilidade de princípios tributários, chegar-se-ia à inevitável conclusão de que o caráter extrafiscal da norma tributária, mesmo que fundamentado em critérios de proporcionalidade, afastaria a aplicação desses princípios.

Portanto, amiúde à metodologia aplicada, pode-se deduzir que a finalidade extrafiscal tem preponderância sobre alguns princípios tributários, afastando a aplicação desses princípios, na medida em que esteja fundamentada em critérios de proporcionalidade. O tributo com finalidade extrafiscal, ou seja, situado dentro dos limites do Direito Econômico-Social e com sua aplicabilidade atual, deverá observar o princípio da PRISMAS: Dir., Pol.Pub. e Mundial., Brasília, v.4, n, 1, p. 98-122, jan/jul. 2007 
proporcionalidade ou da proibição do excesso, mediante a verificação da legitimidade de seus fins, da sua efetividade e imprescindibilidade, bem como da proporcionalidade direta entre o fim buscado e o sacrifício exigido.

\section{A extrafiscalidade e o princípio da justiça social}

O princípio da justiça social-tributária encontra vida, alma e impulso, na virtude da teoria da justiça fundamentada por John Ralws, contida na sua obra "Uma teoria da justiça”, uma das mais importantes obras desenvolvidas no Século XX. Ela serve de fundamento ao princípio da Justiça Social almejada quando verificamos a aplicabilidade da extrafiscalidade em detrimento de princípios tributários, de acordo com alguns aspectos específicos. Pretende John Ralws “elaborar uma teoria da justiça que seja uma alternativa para essas doutrinas que há muito tempo dominam a nossa tradição filosófica - a utilitária e a intuicionista”. 22

De acordo com John Ralws, a sociedade pode ser vista como uma associação mais ou menos auto-suficiente de pessoas que, em suas relações, reconhecem a existência de regras de conduta como obrigatórias, as quais, na maioria das vezes, são cumpridas e obedecidas, especificando um sistema de cooperação social para realizar o bem comum.

Seguindo esse entendimento, surgem tanto identidade de interesses como conflito de interesses entre as pessoas, pois estas podem acordar ou discordar pelos mais variados motivos quanto às formas de repartição dos benefícios e dos ônus gerados no convívio social. É precisamente aí que os princípios da justiça social desempenham seu papel. Nas palavras de John Ralws:

Exige-se um conjunto de princípios para escolher entre várias formas de ordenação social que determinam essa divisão de vantagens e para selar um acordo sobre as partes distributivas adequadas. Esses princípios são os princípios da justiça social: eles fornecem um modo de atribuir direitos e deveres nas instituições básicas da sociedade e definem a distribuição apropriada dos benefícios e encargos da cooperação social. ${ }^{23}$

De acordo com John Ralws, existem dois princípios da justiça social. O primeiro ressalta que cada pessoa deve ter um direito igual ao mais abrangente sistema de liberdades básicas iguais que seja compatível com um sistema semelhante de liberdades para as outras. Por sua vez, para o segundo, as desigualdades sociais e econômicas devem ser ordenadas de

\footnotetext{
${ }^{22}$ RAWLS, John. Uma teoria da justiça. São Paulo: Editora Martins Fontes, 2000, p. 3.

${ }^{23}$ Idem, p. 5.

PRISMAS: Dir., Pol.Pub. e Mundial., Brasília, v.4, n, 1, p. 98-122, jan/jul. 2007
} 
tal modo que sejam ao mesmo tempo: (I) consideradas como vantajosas para todos dentro dos limites do razoável, e (II) vinculadas a posições e cargos acessíveis a todos.

Tais princípios, segundo John Ralws, aplicam-se à estrutura básica da sociedade, presidem a atribuição de direitos e deveres e regem as vantagens sociais e econômicas advindas da cooperação social. John Ralws observa ainda que os dois princípios são um caso especial de uma concepção mais geral da justiça assim expressa:

Todos os valores sociais - liberdade e oportunidade, renda e riqueza, e as bases sociais da auto-estima - devem ser distribuídos igualitariamente, a não ser que uma distribuição desigual de um ou de todos esses valores traga vantagens para todos. ${ }^{24}$

Vê-se, pois, que os princípios de justiça social têm um nítido caráter "substancial” e não meramente "formal” na teoria de John Ralws. Assim, o objeto primário da justiça, para John Ralws, é a estrutura básica da sociedade, ou mais exatamente, a maneira pela qual as instituições sociais mais importantes distribuem direitos e deveres fundamentais e determinam a divisão de vantagens provenientes da cooperação social. Seguindo esse entendimento, os princípios de justiça social, que regulam a escolha de uma constituição política, devem ser aplicados, em primeiro lugar, às profundas e difusas desigualdades sociais, supostamente inevitáveis na estrutura básica de qualquer sociedade.

De acordo com a interpretação e a aplicação sistemática desse princípio, poder-seia dizer que o STF aplicou intuitivamente tal princípio, ao entender que a instituição de incentivos fiscais para empresas que contratassem empregados com mais de quarenta anos, estaria respeitando a relação entre meio e fim da lei. Ou seja, um incentivo seria atribuído a quem contratasse empregados com mais de quarenta anos. O objetivo da lei atende ao princípio da justiça social, sendo uma forma de "justiça como eqüidade” (justice as fairness).

É nesse ínterim que se encontra a preponderância do caráter extrafiscal da norma em face de princípios tributários, baseado em critérios de proporcionalidade, sendo uma forma de "justiça como eqüidade”, como dizia John Ralws, significando que é uma justiça estabelecida numa posição inicial de perfeita eqüidade entre contribuintes e fisco, e cujas idéias e objetivos centrais constituem uma concepção para uma democracia constitucional, como acontece na implementação de políticas públicas.

${ }^{24}$ Idem, p. 26. 


\section{Os mecanismos da imunidade e da isenção}

Sabe-se, por conseguinte, que o efeito extrafiscal da norma tributária utiliza-se do instrumento financeiro para a provocação de certos resultados econômico-sociais, como reprimir a inflação, evitar o desemprego, restaurar a prosperidade, proteger a indústria nacional, promover o desenvolvimento econômico, nivelar as fortunas ou corrigir a iniqüidade na distribuição da renda nacional e, sobretudo, promover o acesso à educação superior, além de outros objetivos igualmente importantes.

Nesse sentido, a extrafiscalidade da norma tributária fornece a explicação ao fato de que, praticamente, todos os problemas que convergem para a área do tributo podem ser estudados do o ângulo oposto: o da isenção e da imunidade. Tal possibilidade apresenta certa simetria com o poder de tributar.

Na doutrina pátria, sobejam conceitos de imunidade e principalmente de isenção, que variam conforme o conceito unitário ou dualista de tributo adotado. A imunidade é tida como limitação ao poder de tributar ou como norma de estrutura, que subordina a feitura de normas de comportamento. A isenção, como dispensa do pagamento de tributo devido, norma de estrutura e norma de não-incidência é uma forma excludente da obrigação.

Para Sacha Calmon Navarro Coêlho, a isenção, tal qual a imunidade, é "simples previsão legislativa de intributabilidade” ${ }^{25}$, é regra que atua juntamente com as previsões impositivas, no aspecto material da norma tributária, definindo sua dimensão. O autor propõe que a hipótese da norma tributária seja composta por "fatos tributáveis" (segundo a regra impositiva), subtraídos os fatos isentos e imunes.

Sacha Calmon Navarro Coêlho, em prestígio à técnica jurídica, distingue a isenção e a imunidade dos demais institutos exoneratórios, portanto aquelas atuam no campo da hipótese da norma tributária, enquanto os estes atuam na conseqüência da norma. A distinção essencial entre a imunidade e a isenção para o jurista mineiro é o status constitucional da imunidade, inexistente na isenção. Destaca-se também que a imunidade é, inequivocamente, instituto que delimita a competência tributária impositiva.

Com relação ao fundamento ontológico, isenções e imunidades também apresentam aspectos em comum. Podem existir, segundo Marcus de Freitas Gouvêa ${ }^{26}$ :

\footnotetext{
${ }^{25}$ COELHO, Sacha Calmon Navarro. Teoria geral do tributo e da exoneração tributária. Belo Horizonte: Del Rey, 2000, p. 153.

${ }^{26}$ GOUVÊA, Marcus de Freitas. A extrafiscalidade no direito tributário. Belo Horizonte: Del Rey, 2006, p. 211. 
1) como instrumento em favor da capacidade contributiva, para adequar a previsão genérica e abstrata da norma impositiva;

2) ou, como instrumento de política pública, independente da capacidade econômica dos contribuintes. No primeiro caso, tem-se a imunidade recíproca e aquela que beneficia particulares que exercem munus público, como a dirigida a instituições de educação e de assistência social sem fins lucrativos e a isenção da primeira faixa de renda do IRPF (Imposto de Renda Pessoa Física), que protege o chamado mínimo existencial.

No segundo grupo, encontra-se a imunidade dos livros, revistas e periódicos, que, não obstante possam representar mercado promissor constituem-se veículo de cultura que o Estado pretende preservar, assim como isenções a determinados produtos, cujo mercado incipiente o Estado quer estimular.

As isenções podem ser classificadas em condicionais e incondicionais, temporárias e por prazo indeterminado, gerais e individuais, regionais ou irrestritas. A isenção incondicional é aquela que independe da comprovação do preenchimento de qualquer requisito pelo contribuinte, a ser avaliada pelo fisco. É o caso da isenção da primeira faixa de renda do imposto de renda da pessoa física. A isenção condicional é que depende do preenchimento de algum requisito pelo contribuinte, seja a realização de uma conduta, seja uma situação jurídica, seja uma situação fática. Necessariamente, as isenções incondicionadas serão gerais, alcançando todos os contribuintes ou fatos, conforme seja o benefício subjetivo ou objetivo. As isenções condicionais serão individuais e dependerão da análise de cada caso pela Administração Tributária.

A isenção pode, também, ser temporária, com prazo preestabelecido, mas pode ser fixada por tempo indeterminado, facultando-se sua revogação por lei posterior ou sua extinção por ato administrativo, se o beneficiário deixou de cumprir os requisitos para sua concessão.

O Código Tributário Nacional (CTN), em seu art. 176, parágrafo único, dispõe que “a isenção pode ser restrita a determinada região do território da entidade tributante, em função de condições a ela peculiares.” Em regra, restringe-se aos impostos, conforme disposição do art. 177 também do CTN.

As imunidades aplicam-se, em regra, aos impostos. Algumas são gerais, sem a imposição de condições. Por exemplo, as dos partidos políticos, que têm efeito extrafiscal ligado à organização política nacional. Outras, como as das instituições de educação sem fins lucrativos, que prestigiam a finalidade extrafiscal de incentivo à educação, são reconhecidas apenas àqueles que comprovem o preenchimento dos requisitos legais (art. 14 do CTN).

Também há imunidades relativas apenas a contribuições para a seguridade social, que prestigiam as entidades beneficentes de assistência social. Como sói ocorrer, a 
Constituição da República reconhece a intributabilidade de pessoa privada que se dedica a prestar assistência social gratuita, que é dever do próprio Estado. Assim, a norma contém efeito extrafiscal de estímulo à atividade assistencial.

De acordo com a classificação, imunidades e isenções apresentam efeitos extrafiscais distintos. O efeito de indução do comportamento mediante vantagem fiscal será específico a determinados contribuintes que preenchem os requisitos legais, se a isenção for individual. Será geral nas isenções gerais.

É importante dizer que mesmo a isenção geral pode vir dotada de carga extrafiscal. Por exemplo, se direcionada, objetivamente, à produção do álcool combustível, estimula seu consumo em prejuízo do consumo de gasolina. Se direcionada, subjetivamente, aos fabricantes de malhas têxteis, favorece o aparecimento de indústrias desse tipo de vestuário em detrimento dos curtumes.

O efeito extrafiscal de isenções pode ser regionalizado em favor do desenvolvimento de certas partes do país ou do estado, conforme o benefício seja federal ou estadual. Porém, pode ser irrestrito territorialmente, quando os efeitos extrafiscais fazem-se sentir em todo o território do ente federado.

Mizabel Derzi e Sacha Calmon Navarro Coelho ${ }^{27}$, em parecer sobre o tema de benefícios regionais, especificamente do estabelecimento de alíquotas diferenciadas do IPI para produtores de açúcar, de acordo com a região em que se encontram, afirmam que o benefício regionalizado só é constitucional se destinado ao desenvolvimento da região. No caso analisado, com base na Lei n. ${ }^{\circ}$ 8.393, de 30 de dezembro de 1991, os autores entendem que o beneficio destinava-se apenas aos industriais de certas regiões, e constituía uma penalização ao povo e aos empresários de outras regiões. Esse raciocínio não se restringe ao caso apreciado pelos autores, mas estende-se, igualmente, a toda espécie de benefício, inclusive isenções.

Cumpre registrar, ainda, a exigência de benefícios com prazo determinado ou indeterminado. As isenções temporárias podem, por exemplo, incentivar o início de uma atividade, estabelecendo-se a tributação normal com data marcada, de sorte que os empresários possam programar-se e capitalizar-se de maneira planejada. Nesses casos, embora o efeito extrafiscal não perdure além do tempo em que a norma encontrar-se em vigor, há a vantagem de impossibilidade de revogação do benefício para os contribuintes que começarem a gozá-lo. De outra forma, as isenções por prazo indeterminado não permitem que

\footnotetext{
${ }^{27}$ DERZI, Mizabel; COÊLHO, Sacha Calmon Navarro. Direito tributário atual. Rio de Janeiro: Forense, 1995, p. 349. 
o destinatário do benefício faça programações por prazo certo, pois podem ser revogadas a qualquer momento, obedecidas as regras de concretização do princípio da não surpresa.

Pode-se inferir que de uma forma geral a justificativa doutrinária para a existência das normas imunizantes e isencionais está ligada a conceitos de natureza política e social de determinada sociedade em dado período histórico, com a finalidade de garantir as liberdades individuais, via exoneração de tributos, para não embaraçar a existência de direitos socialmente relevantes. Assim, as normas de impedimento da competência tributária voltamse para a liberdade de expressão, o acesso à cultura e à liberdade religiosa. Além disso, voltam-se às atividades desempenhadas pelas instituições de educação e assistência social sem lucratividade, às entidades sindicais de trabalhadores, partidos políticos e suas fundações.

Para justificar a necessária existência das normas imunizantes e isencionais, Regina Helena Costa invoca a teoria da densificação das normas constitucionais concebida por Canotilho, entendendo que as normas imunizantes densificam princípios estruturantes no sentido jurídico-constitucional e político-constitucional. Portanto:

[...] os princípios federativo e da autonomia municipal são densificados pela imunidade recíproca; que o princípio da isonomia é densificado pela imunidade conferida às instituições de educação e assistência social sem fins lucrativos; que o princípio do pluralismo partidário é densificado pela imunidade outorgada aos partidos políticos; que a liberdade de expressão e o livre acesso à cultura são densificados pela imunidade referente aos livros; que a liberdade de culto é densificada pela imunidade dos templos - e assim por diante. ${ }^{28}$

Pode-se entender, portanto, que as imunidades e isenções são meios de realização de extrafiscalidade no âmbito constitucional. Nesse sentido o magistério de Geraldo Ataliba assenta que a extrafiscalidade "consiste no uso de instrumentos tributários para obtenção de finalidades não-arrecadatórias, mas estimulantes, indutoras ou coibidoras de comportamentos, tendo em vista outros fins, a realização de outros valores constitucionalmente consagrados.”29 Então, pode-se afirmar que os princípios mais valorosos inseridos na Constituição, tais como a segurança jurídica, a justiça e o bem comum, relacionados aos direitos fundamentais, estão presentes essencialmente na imunidade e isenção tributária, cuja natureza é extrafiscal.

As imunidades tributárias são normas de proteção de outros direitos fundamentais e constituem, ao mesmo tempo, direitos e garantias de outros direitos e firmam-se com o teor do art. XIX da Declaração Universal dos Direitos Humanos assim disposto ${ }^{30}$ : “Toda pessoa

\footnotetext{
${ }^{28}$ COSTA, Regina Helena. Imunidades tributárias. São Paulo: Dialética, 2001, p. 59.

${ }^{29}$ ATALIBA, Geraldo. IPTU e progressividade. RDP 93/223.

${ }^{30}$ COSTA, Regina Helena. Ob. Cit. p. 85.

PRISMAS: Dir., Pol.Pub. e Mundial., Brasília, v.4, n, 1, p. 98-122, jan/jul. 2007
} 
tem direito à liberdade de opinião e expressão; este direito inclui a liberdade de, sem interferências, ter opiniões e de procurar, receber e transmitir informações e idéias por quaisquer meios e independentemente de fronteiras”.

De uma forma geral, verifica-se que isenções e imunidades atuam estimulando comportamentos mediante a redução da carga tributária, razão pela qual constata-se, que os institutos apresentam potencialidade extrafiscal marcante.

\section{Conclusão}

Sendo o processo de implementação de políticas públicas reflexo de toda uma fundamentação do Estado Contemporâneo, a finalidade extrafiscal da norma tributária emerge como um arranjo institucional legítimo na formulação, mecanização e implementação para que uma política pública seja viável. Nesse sentido, a finalidade extrafiscal da norma tributária constitui-se na aplicação de um modelo jurídico-tributário para a consecução de objetivos que preponderam sobre os fins simplesmente arrecadatórios de recursos financeiros para o Estado. O valor finalístico da extrafiscalidade que o legislador incute na lei tributária, portanto, deve atender às necessidades na condução da economia ou correção de situações sociais indesejadas ou mesmo possibilidade de fomento a certas atividades ou ramo de atividades de acordo com os preceitos constitucionais, razão pela qual há uma vasta casuística a respeito do tema.

Sob o prisma do Direito Econômico, os tributos cuja finalidade seja essencialmente extrafiscal devem obedecer ao princípio da proporcionalidade ou da proibição do excesso, entendimento também esposado pelo Supremo Tribunal Federal brasileiro, o que é uma forma de “justiça como eqüidade” (justice as fairness), como preconizava John Rawls. Assim, o efeito extrafiscal da norma tributária utiliza-se do instrumento financeiro para a provocação de certos resultados econômico-sociais, como reprimir a inflação, evitar o desemprego, restaurar a prosperidade, proteger a indústria nacional, promover o desenvolvimento econômico, além de outros objetivos não menos nobres. Assim, a extrafiscalidade da norma tributária fornece a explicação ao fato de que praticamente todos os problemas que convergem para a área do tributo podem ser estudados sobre o ângulo oposto: o da isenção e da imunidade tributária.

Pode-se inferir, nesse sentido, que a utilização da extrafiscalidade (isenção ou imunidade) na implementação de políticas públicas tem por finalidade estimular ações afirmativas, indutoras ou coibidoras de comportamentos, tendo em vista a realização de 
valores constitucionalmente consagrados, como o direito à educação, sobretudo no que diz respeito à sua forma de acesso.

Artigo recebido em março de 2007

Aceito para publicação em abril de 2007

\section{Referências}

AMARO, Luciano. Direito tributário brasileiro. 2. ed. Revisada. São Paulo: Saraiva, 1998. ATALIBA, Geraldo. IPTU e progressividade. RDP 93/223.

BALEEIRO, Aliomar. Introdução à ciência das finanças. 14.ed, atualizada por Flávio Bauer Novelli, Rio de Janeiro: Editora Forense, 1995.

BARROS. Suzana de Toledo. O princípio da proporcionalidade e o controle de constitucionalidade das leis restritivas de direitos fundamentais. 2. ed. Brasília: Editora Brasília Jurídica, 2000.

BRASIL. Constituição da República Federativa do Brasil. Brasília: Planalto, 2006. Disponível em: < http://www.planalto.gov.br > Acesso em: 22 nov. 2006.

CARVALHO, Paulo de Barros. Curso de direito tributário. 9. ed. rev., São Paulo: Editora Saraiva, 1997.

COELHO, Sacha Calmon Navarro. Teoria geral do tributo e da exoneração tributária. 3. ed., Belo Horizonte: Del Rey, 2000.

COSTA, Regina Helena. Imunidades tributárias. 2.ed., revista e atualizada, São Paulo: Malheiros, 2006.

DERZI, Mizabel; COÊLHO, Sacha Calmon Navarro. Direito tributário atual. Rio de Janeiro: Forense, 1995.

FERNANDES, Simone Lemos. Contribuições neocorporativas. Belo Horizonte: Del Rey, 2005.

FONROUGE, Juliani. Derecho financiero. 3. ed., v. I, Buenos Aires: Editora Depalma, 1976. GOUVÊA, Marcus de Freitas. A extrafiscalidade no direito tributário. Belo Horizonte: Editora Del Rey, 2006.

MACHADO, Hugo de Brito. Curso de direito tributário.16.ed., São Paulo: Malheiros, 1999 
MALISKA, Marcos Augusto. O direito à educação e a Constituição. Porto Alegre: Sérgio Fabris Editor, 2001.

MEIRELLES, Hely Lopes. Direito administrativo brasileiro. 25.ed., São Paulo: Editora Malheiros, 2000.

MEIRELLES, Hely Lopes. Direito municipal brasileiro. 6. ed. atualizada por Izabel C. L. Monteiro e Yara D. P. Monteiro. São Paulo: Editora Malheiros, 1993.

OLIVEIRA, José Marcos Domingues de. Contribuições sociais. In: Cadernos de pesquisas tributárias. v. 17, São Paulo: Resenha Tributária e Centro de Extensão Universitária, 1992.

OLIVEIRA, José Marcos Domingues de. O Conteúdo da extrafiscalidade e o papel das Cides. Efeitos decorrentes da não-utilização dos recursos arrecadados ou da aplicação em finalidade diversa. Revista Dialética de Direito Tributário, São Paulo: Dialética, n. 131, ago. 2006.

RAWLS, John. Uma teoria da justiça. 2.ed., São Paulo: Editora Martins Fontes, 2002. 


\section{Resumo}

O presente estudo visa realizar uma análise sistemática sobre a utilização da finalidade extrafiscal da norma tributária como instrumento de implementação de políticas públicas. $\mathrm{O}$ artigo contextualiza o Estado contemporâneo na perspectiva de situar a atividade estatal brasileira no âmbito do que se convencionou a chamar de Globalização. Busca-se, a partir daí, um modelo de teórico de Estado, levando-se em consideração a sua política contemporânea aplicada e a redefinição do papel do Estado em face da Globalização. Em seguida, o artigo analisa a finalidade extrafiscal da norma tributária como mecanismo de implementação de políticas públicas situando tal procedimento no Sistema Tributário Brasileiro a partir dos objetivos extrafiscais dos tributos e seus valores jurídico-sociais, como no incentivo à educação.

Palavras-chave: Políticas Públicas; Extrafiscalidade; Isenção Fiscal.

\begin{abstract}
This study aims to achieve a systematic analysis on the use of extrafiscal purposes of tax norms as an instrument to implement public policy. The article outlines the context of the contemporary State, while attempting to position the Brazilian state activity amidst the so called globalization process. From this point, the study seeks a theoretical model of the state, taking in consideration its contemporary policy and a new definition of the state under the influence of the globalization process. Afterwards, the study analyzes tax norms' extrafiscal purposes and their social and legal values as an incentive to education.
\end{abstract}

Keywords: .Public Policies; Extrafiscality; Fiscal exemption. 